\title{
Methods for the administration of EDAR pathway modulators in mice
}

Sonia Schuepbach-Mallepell ${ }^{1}$, Christine Kowalczyk-Quintas ${ }^{1}$, Angela Dick ${ }^{2}$, Mahya Eslami ${ }^{1}$,

Michele Vigolo $^{1}$, Denis J. Headon ${ }^{3}$, Michael Cheeseman ${ }^{3}$, Holm Schneider ${ }^{2}$ and Pascal Schneider ${ }^{1}$

${ }^{1}$ Department of Biochemistry, University of Lausanne, CH-1066 Epalinges, Switzerland

${ }^{2}$ Department of Pediatrics, University of Erlangen-Nürnberg, 91054 Erlangen, Germany

${ }^{3}$ Roslin Institute and Royal (Dick) School of Veterinary Studies, University of Edinburgh, Roslin EH25 9RG, UK.

Corresponding Author: Pascal Schneider, Department of Biochemistry, University of Lausanne, Boveresses 155, CH-1066 Epalinges, Switzerland

Phone: +41 216925709

Fax: +41 216925705

E-mail: pascal.schneider@unil.ch

Running head: Pharmacological modulation of the EDAR pathway in mice Abbreviations: EDA, ectodysplasin A; EDAR, EDA receptor. 


\begin{abstract}
Genetic deficiency of ectodysplasin A (EDA) causes X-linked hypohidrotic ectodermal dysplasia, a congenital condition characterized by the absence or abnormal formation of sweat glands, teeth and several skin appendages. Stimulation of the EDA receptor (EDAR) with agonists in the form of recombinant EDA or anti-EDAR antibodies can compensate for the absence of $E d a$ in a mouse model of Eda deficiency, provided that agonists are administered in a timely manner during fetal development. Here we provide detailed protocols for the administration of EDAR agonists or antagonists, or other proteins, by the intravenous, intraperitoneal and intra-amniotic routes as well as protocols to collect blood, to visualize sweat gland function and to prepare skulls in mice.
\end{abstract}

Key words: EDAR signaling, protein replacement therapy, amniotic fluid, route of administration, ectodermal dysplasia. 


\section{Introduction}

Mutations affecting the Ectodysplasin A gene (EDA) cause the disease X-linked hypohidrotic ectodermal dysplasia both in mice and humans [1,2]. Mutations of the genes encoding the EDA receptor or the signaling adapter molecule EDAR-associated protein with a death domain (EDARADD) cause autosomal forms of hypohidrotic ectodermal dysplasia with phenotypes virtually indistinguishable from that of EDA deficiency [3-5]. In patients with X-linked hypohidrotic ectodermal dysplasia, anhidrosis and subsequent lack of thermoregulation is a major problem [6]. Experimental strategies have been implemented with the aim of attenuating detrimental effects of $E D A$ deficiency. In mice, ectopic expression of an $E d a$ transgene in the skin under the control of the keratin 14 promoter can rescue many features of the defect, including sweat gland development. Most rescued structures were maintained when the transgene was switched off post-development, indicating that Eda signals are more important to induce the formation of ectodermal appendages than to maintain them [7]. Similar observations were made when an active recombinant form of EDA fused to the Fc portion of an IgG1 (Fc-EDA) was administered intravenously to pregnant $E d a$-deficient dams, and presumably transported to the fetal circulation via a transplacental antibody transport machinery [8]. Under these conditions, Eda-deficient fetuses exposed to Fc-EDA gained a phenotype that was close to wild-type in many respects and that was maintained long-term despite discontinuation of Fc-EDA administration. When the protein was administered intraperitoneally to newborn $E d a$-deficient mice at relatively late time points compared to in utero treatment of fetuses, treatment efficacy decreased sharply with time up to the point of becoming totally inefficient at inducing the formation of ectodermal appendages one week after birth [8]. This exquisite time-dependence of treatment efficacy can 
explain the failure of a phase II clinical trial aimed at treating newborn $E D A$-deficient human patients with Fc-EDA [9]. The lack of efficacy was interpreted as a likely consequence of mistargeting the time window during which treatment can work. In mice, treatment of Edadeficient fetuses with Fc-EDA by the intra-amniotic route happened to be very successful, with results equaling those obtained for the transplacental route [10]. Indeed, although Fc-EDA administered into the amniotic fluid is outside fetuses and cannot directly access EDAR, the drug can nevertheless reach the fetal circulation by a mechanism that is dependent on the neonatal Fc receptor (FcRn). This was demonstrated when fetuses deficient for both Eda and Fcgrt (Fcgrt encodes FcRn) could not respond to treatment with Fc-EDA, while neighboring fetuses from the same litter deficient for Eda but wild-type for Fcgrt responded to treatment [9]. The intra-amniotic route of administration was deemed adequate for the treatment of human fetuses because it provides several advantages including a potential reservoir function of the amniotic fluid and little leakage of the recombinant protein into the maternal circulation [10]. Indeed, three human male fetuses carrying $E D A$ null mutations who received Fc-EDA via the intra-amniotic route benefitted from restoration of their sweating ability, with beneficial outcome also on teeth and salivary glands [9]. Antibodies that target the EDA-EDAR pathway in positive or negative ways can prevent or induce ectodermal dysplasia phenotypes in animal models [11,12]. In Eda-deficient mice, in utero treatment of affected fetuses with an anti-EDAR antibody via the transplacental route restored nasal submucosal glands and the paired nasopharyngeal submucosal glands that protect the opening of each of the Eustachian tubes. The seromucous glandular secretions aid mucociliary clearance and prevent rhinitis and entry of foreign bodies into the middle ear bulla, the presence and persistence of which may cause otitis media [13]. In adult mice, EDA can regulate the function 
of pre-existing structures, in particular hair-associated sebaceous glands which grow or shrink in response to increased or decreased EDA levels [7,14].

Here we detail basic procedures for the administration of EDAR agonists via the intravenous, intraperitoneal and intra-amniotic routes in mice. The former are commonly performed methods, but the latter requires surgery to access fetuses. All of them were instrumental in several of the aforementioned publications. Blood sampling via the facial vein is also described, because analysis of EDAR agonists in the circulation can be useful. Monitoring restoration of functional sweat glands has been a recurring theme during the development of pharmacological modifiers of the EDA-EDAR pathway, due to their clinical importance in ectodermal dysplasia. We describe the protocol that we have used for a starch-iodine test to assess sweating ability. This test takes advantage of iodine's property of forming an intensely dark complex with starch in aqueous solutions. Iodine dissolved in ethanol is first applied onto the skin, followed by a suspension of starch in oil. It is only at the specific locations of sweat gland secretion that black starch-iodine complexes form. Finally, we describe the method that we have been using for mouse skull preparation, which aids the evaluation of dental phenotypes. With regard to the correction of ectodermal dysplasia phenotypes in $E d a$-deficient mice, best results are obtained when fetuses are exposed to EDAR agonists between embryonic gestational days 13.5 to birth, which can be achieved either by intravenous injection of the pregnant dam or by direct intra-amniotic administration. Intraperitoneal administration of agonists in newborn $E d a$-deficient pups can only correct some defects (in particular tail hair and sweat glands). In all cases, effects are dosedependent and can be conditioned by the half-life of the drug. For drugs with a shorter half-life, higher doses or repeated administration can be beneficial, however repeated administration cannot be performed in mice via the intra-amniotic route with the described procedure. 


\section{Materials}

The local institutional animal care and use committee and the Office Vétérinaire Cantonal du Canton de Vaud approved animal experiments performed in this study (authorization 1370.7 to PS). Mice were handled according to Swiss Federal Veterinary Office guidelines.

A precise description of the materials that have been used is provided, but similar equivalent material or reagents can also be used.

\subsection{Antibodies and Recombinant Proteins}

1. Fc-EDA (EdimerPharmaceuticals): Fc-EDA is a recombinant protein comprising the Fc portion of an immunoglobulin G1 and the receptor-binding domain of human EDA1 (amino acids 238391). This protein was produced according to Good Manufacturing Practice regulations, and was provided as a drug product under the name of EDI200, at a concentration of $5 \mathrm{mg} / \mathrm{mL}$ in a sterile solution of $20 \mathrm{mM}$ sodium phosphate, $300 \mathrm{mM}$ sodium chloride, pH 7.2, 0.02\% Polysorbate 20. Store the protein frozen at $-70^{\circ} \mathrm{C}$ until use [9].

Alternatively, recombinant Fc-EDA can be produced in Chinese Hamster Ovary cells (CHO-S, Thermoscientific) and affinity-purified on Protein A-Sepharose mAbSelect Xtra (GE Healthcare) [8].

2. Agonist anti-EDAR mouse monoclonal IgG1 antibodies (mAbEDAR1 or mAbEDAR3) or function-blocking anti-EDA mouse monoclonal IgG1 antibodies (EctoD2 or EctoD3): Purify them from conditioned media of hybridoma cultures by affinity chromatography on Protein G (GE Healthcare) $[11,12]$. Store the antibodies frozen at $-70^{\circ} \mathrm{C}$ in sterile PBS at concentrations of 1 to 5 $\mathrm{mg} / \mathrm{mL}$ until use. Endotoxin levels should be lower than $1 \mathrm{EU} / \mu \mathrm{g}$. 


\subsection{Anesthesia}

1. Combi-vet anesthesia system table system (Rothacher AG).

2. Isoflurane Attane ad us. Vet. $250 \mathrm{~mL}$ (Provet AG Covetrus).

\subsection{Blood Collection}

1. Disposable sterile blood lancets.

\subsection{Intravenous and Intraperitoneal Injections in Adult Mice}

1. Syringe: insulin syringe microfine U-100 insulin $0.5 \mathrm{~mL}, 0.33 \mathrm{~mm}(29 \mathrm{G}), 12.7 \mathrm{~mm}$ (BD medical).

2. Red lamp equipped with a $175 \mathrm{~W}$ infrared bulb (Philips AG).

3. Restrainer for normal mice: made of two pieces, broom and holder. Broom style rodent restrainer, reference 551-BSRR (for 15-30 g animals) and holder, reference 551-H, Indulab.

4. Restrainer for mice in late pregnancy: Broom style rodent restrainer, reference 552-BSRR (for 30-120 g animals) and holder, reference 552-H, Indulab.

\subsection{Intraperitoneal Injections in Newborn Mice}

1. Hamilton syringe: Hamilton glass syringe 710RN $100 \mu \mathrm{L}$ without needle (Wicom International $\mathrm{AG}$ ).

2. Needles: Hamilton neuros replacement needle, small hub RN NDL, 0.5 inch, point style 4/15, 33G (Wicom International AG).

\subsection{Intra-amniotic Fluid Injections in Pregnant Mice}


1. Dry heating bath: SUB Aqua 5 Plus (Grant instruments).

2. Hamilton syringe with 33G needle (see Subheading 2.5).

3. Parafilm.

4. Analgesia: Paracetamol (Dafalgan) powder $250 \mathrm{mg}$ (Bristol-Myers Squibb SA).

5. Analgesia: Buprenorphin (Temgesic) inj. Sol. $0.3 \mathrm{mg} / \mathrm{mL}$ (Indivior).

6. Heating mat: Solis thermopad (Solis Apparatefabriken AG).

7. Heating lamp: Red lamp equipped with a $175 \mathrm{~W}$ infrared bulb (Philips AG).

8. Scissors: Fine, straight, sharp.

9. Two forceps: Standard pattern, straight, serrated.

10. Needles and stitches (for absorbable suture): MultiPass needles coated vicryl, 4-0, P-3

(13 mm 3/8c), $45 \mathrm{~cm}$, reference MPV494 (Johnson and Johnson international, ETHICON).

11. Ophthalmic gel: Lacryvisc gel (Alcon).

12. Plastic syringe: $3 \mathrm{~mL}$, sterile.

\subsection{Sweat Test}

1. Sublimated iodine: reference 1047610100, Merckmillipore, Switzerland.

2. Absolute ethanol: reference 10428671, ThermoFischer Scientific, Switzerland.

3. Corn starch, olive oil and cotton buds: any commercial store.

4. Strong table light: for example JANSJÖ lamp, Ikea, Switzerland.

5. Camera with macro option: for example Canon Ixus $12 x(4.0-4.8 \mathrm{~mm})$.

6. Iodine solution (5\%): $0.75 \mathrm{~g}$ of iodine in $15 \mathrm{~mL}$ of $100 \%$ ethanol

\subsection{Preparation of Mouse Skulls}


1. Pentobarbital (also known as pentobarbitone) (Esconarkon) at $300 \mathrm{mg} / \mathrm{mL}$ (Streuli Pharma) (see Note 1).

2. Fine forceps: Straight.

3. Fine forceps: Curved.

4. Scissors: Standard pattern.

5. Fine scissors: straight, sharp.

6. Needle: Sterican 21G, 0.8x80 mm (B. Braun).

7. Plastic syringe: $10 \mathrm{~mL}$ any brand.

8. TEN buffer: 10 mM Tris-HCl, pH 8, 5 mM EDTA, $100 \mathrm{mM} \mathrm{NaCl,} \mathrm{0.5 \%} \mathrm{SDS.}$

9. Proteinase K: Stock at $20 \mathrm{mg} / \mathrm{mL}$ (Applichem).

10. TEN buffer, proteinase K: Freshly prepared solution of $50 \mu \mathrm{g} / \mathrm{mL}$ of proteinase K in TEN buffer.

11. $30 \%$ hydrogen peroxide.

12. Stereomicroscope (Leica M205FA) equipped with a cooled color CCD camera (Leica, DFC300FX R2).

13. LAS AF6000 software (Leica).

\section{METHODS}

\subsection{Intravenous Injection in Adult Mice}

1. The Swiss Federal Veterinary Office currently recommends volumes for intravenous injections of up to $5 \mathrm{~mL} / \mathrm{kg}$, i.e. $100 \mu \mathrm{L}$ for a $20 \mathrm{~g}$ mouse or $150 \mu \mathrm{L}$ for a $30 \mathrm{~g}$ mouse (see Note 2 ).

2. Place mouse cage under the red lamp to warm the mouse and stimulate the dilatation of the veins for about 10-15 minutes. The lamp is at $30 \mathrm{~cm}$ from the bottom of the cage (Fig. 1a) (see Note 3 ). 
3. Transfer the mouse to a restrainer. Put the mouse in a lateral position because veins are on the lateral part of the tail.

4. Hold the tail straight with the non-dominant hand (i.e. the left hand for a right-handed experimenter) toward the floor with an angle of about $45^{\circ}$ from the horizontal (Fig. 1b).

5. Apply a fine spray of $70 \%$ ethanol onto the tail. This will cause the lateral vein to become more visible.

6. Insert the needle of an insulin syringe just below the skin. The needle should be almost parallel to the tail (Fig. 1c).

7. Once the needle is inside the vein, press the piston. This should deliver the solution easily, without requiring application of firm pressure. If the solution cannot be delivered with gentle pressure, then this means that the needle is not inside the vein and it must be removed, repositioned and reinserted at another site nearer the tail base for injection.

\subsection{Intraperitoneal Injection in Adult Mice}

1. The Swiss Federal Veterinary Office currently recommends volumes for intraperitoneal injections of up to $20 \mathrm{~mL} / \mathrm{kg}$, i.e. $400 \mu \mathrm{L}$ for a $20 \mathrm{~g}$ mouse or $600 \mu \mathrm{L}$ for a $30 \mathrm{~g}$ mouse.

2. Immobilize the mouse in one hand and hold the mouse with the head towards the floor.

3. Insert the needle on the left side of the mouse belly (from the experimenter's point of view) with an angle of about $45^{\circ}$, at about $1.5 \mathrm{~cm}$ from the base of the tail, and inject the solution.

\subsection{Intraperitoneal Injection in Newborn Mice}

1. Injection volume of up to $15 \mu \mathrm{L} /$ pup, ideally $10 \mu \mathrm{L} /$ pup. (see Note 4). 
2. Fill the Hamilton syringe equipped with the $33 \mathrm{G}$ needle. For this purpose, place a drop of the solution to inject on a clean piece of parafilm and suck from that drop into the syringe (see Note 5).

3. Gently hold the pup in one hand by slightly pinching the skin of the neck. Skin on the belly should be stretched to the minimum.

4. Insert the needle on the lower right quadrant of the mouse belly (from the experimenter's point of view), coming from the right side with an angle of about $30^{\circ}$, without touching the liver or bladder that can be seen through the partially transparent skin. Slowly inject the solution, leaving the needle in place for a few seconds after completing delivery, then slowly remove the needle to avoid leak of the injected solution (see Note 6).

\subsection{Blood Collection in Adult Mice by Puncture of the Facial Vein}

1. The Swiss Federal Veterinary Office currently recommends to collect blood volumes not greater than $280 \mu \mathrm{L}$ for a $20 \mathrm{~g}$ mouse and for a period of 14 days (in one or several bleeds) (see Note 7). 2. Switch on the gas anesthesia apparatus, check that the tank supplying isoflurane is full and check that the humidifying chamber contains sufficient water (see Note 8).

3. Set the oxygen input flow on $0.8 \mathrm{~L} / \mathrm{min}$ and the isoflurane on $3 \%$.

4. Place the mouse in the induction chamber and induce a light anesthesia. Proceed to the next step as soon as the mouse loses consciousness.

5. Hold the lightly anesthetized mouse on the side with the non-dominant hand.

6. The facial vein can be localized by drawing two virtual lines, one from the ending edge of the mouth toward the neck and the other from the external edge of the eye toward the throat. The vein is at the intersection, close to the skin surface (Fig. 2). 
7. With the lancet, make a shallow prick of the facial and collect (directly) one or two drops of blood in a tube $[\sim 25-50 \mu \mathrm{L}]$ (see Notes 9, 10).

8. Once the mouse is released, the bleeding spontaneously stops almost immediately.

\subsection{Intra-amniotic Fluid Injections}

This procedure is divided in 4 steps: a) Anesthesia and analgesia. b) Midline laparotomy and injections (Fig. 3a-d). c) Continuous suture of the abdominal wall (Fig. 3e and 4a). d) Interrupted stitching of the skin (Fig. $3 \mathbf{f}$ and $\mathbf{4 b}$ ). The entire surgical procedure should be performed in less than one hour to avoid spontaneous contraction of the uterus and miscarriage.

\subsubsection{Anesthesia and Analgesia}

1. Switch on the gas anesthesia apparatus, check that the tank supplying isoflurane is full and check that the humidifying chamber contains sufficient water.

2. Set the oxygen input flow on $0.8 \mathrm{~L} / \mathrm{min}$ and the isoflurane on $5 \%$.

3. Place the timed-mated pregnant mouse on gestational day 13.5 (E13.5) in the induction chamber and anesthetized it with $5 \%$ isoflurane. With fingers, pinch the hind paw to check that the retraction reflex does not operate. The absence of this pedal reflex indicates that the mouse is anesthetized for surgery.

4. Inject a first dose of analgesic (buprenorphine, $0.1 \mathrm{mg} / \mathrm{kg}$ ) subcutaneously in the back with an insulin syringe.

5. Apply a copious amount of gel on the eyes to avoid eye desiccation. 
6. Place the mouse on its back on absorbing papers, on a pre-warmed heating mat with the snout inserted into the mask (see Note 11).

7. Maintain surgical anesthesia with $2 \%$ isoflurane.

\subsubsection{Midline Laparotomy and Injections}

1. Disinfect the abdominal region with a generous amount of $70 \%$ ethanol.

2. With forceps, lift the skin at the base of the belly, make a small incision with sharp scissors and use this opening to cut the abdominal skin approximately $1.5 \mathrm{~cm}$ towards the head along the midline. (see Note 12).

3. With forceps, lift the abdominal wall (consisting of the muscle layer and the peritoneal membrane) at the base of the abdomen, make a small incision with sharp scissors and extend this incision towards the head along the midline for approximately $1.5 \mathrm{~cm}$.

4. Around the opened skin, place paper tissues moistened with sterile PBS prewarmed to $37^{\circ} \mathrm{C}$.

5. Very gently pull out completely both uterine horns from the abdominal cavity and place them on the paper tissues (Fig. 3a).

6. Hold the amniotic sac carefully with forceps without applying pressure. The fetus can be seen through the partially transparent uterus wall and amniotic fluid.

7. Administer $10 \mu \mathrm{L}$ of drug (e.g. Fc-EDA at $5 \mathrm{mg} / \mathrm{mL}$ ), into the amniotic sacs of each individual fetus using a Hamilton glass syringe with a 33-gauge needle (Fig. 3b). The easiest site of injection to avoid touching the fetus is in front of the belly between the upper and lower limbs (Fig. 3c) (see Note 13). 
8. In between each injection, to preserve temperature and moisture, pour about $3 \mathrm{~mL}$ of sterile PBS pre-warmed to $37^{\circ} \mathrm{C}$ with a 3 mLsyringe over the uterine horns.

9. Carefully place back the uterine horns in the abdominal cavity with forceps. For this purpose, lift one side of the incised abdominal wall with one pair of forceps while gently pushing the closest uterine horn into the cavity with a second pair of forceps. Repeat the operation on the other side (Fig. 3d).

\subsubsection{Continuous Suture of the Abdominal Wall}

1. Lift each side of the opened abdominal wall using two pairs of forceps and line up the edges of the opening.

2. Pierce the abdominal wall with the needle on each side of the opening (Fig. 4c).

3. For the first stitch, pull the needle until there are about $2 \mathrm{~cm}$ of thread remaining on the right side of the opening (Fig. 4d, point 1).

4. Lay the needle on the left side near the mouse.

5. Take forceps in the dominant hand. With forceps in the non-dominant hand, hold the long part of the thread and wrap it clockwise twice around the tip of the forceps (Fig. 4d, points

\section{2,3; Fig. 4e).}

6. Slightly open the forceps and use it to grasp the $2 \mathrm{~cm}$ of thread on the right side of the incision (Fig. 4d, point 4).

7. Gently move hands apart, so that the part of the thread wrapped around the forceps slides off and creates a simple overhand knot (Fig. 4d, point 5).

8. Repeat the procedure to create a second knot but the second time wrap counter clockwise twice around the forceps (Fig 4f, points 6-8). 
9. Cut the excess of thread on the right to leave about $2 \mathrm{~mm}$.

10. Sew continuously by inserting the needle always on the same side of the opening. The thread should look like a spiral (Fig. 4a and $\mathbf{g}$ ).

11. For the last stitch, pull the needle until there is a loop of about $2 \mathrm{~cm}$ of thread remaining on the right side of the wound (Fig. 4h).

12. Repeat steps $\mathbf{4}$ to $\mathbf{8}$, except that the loop of thread is held at step $\mathbf{6}$.

13. Cut all threads at about $2 \mathrm{~mm}$ from the knot (Fig. 4i).

\subsubsection{Interrupted Stitching of the Skin}

1. With a new needle (or the same needle as above if there is enough thread left) cross over to the skin inwards on one side of the opening, then cross over to the skin outwards on the other side of the opening, then perform steps 4 to 8 under the subheading 3.5.3 (Fig. 4d,f,j) and cut the thread on both sides of the knot (Fig. 4b).

2. Stitch the skin by repeating point 30 as many times as necessary. Stitches must be close one to the other to resist the pressure of the growing fetuses in the uterus in late pregnancy (Fig. 3f, 4b).

3. In a cage pre-warmed on a heating mat and devoid of cage enrichments that could rub on the suture, lay the mouse on tissue papers. Provide semi-solid food and drinking water containing Dafalgan at $1.7 \mathrm{mg} / \mathrm{mL}$. Without further disturbance, let the mouse wake up and recover for $2-3 \mathrm{~h}$, then return the cage to the housing rack.

4. Provide the mouse with a second subcutaneous injection of buprenorphine the day after the surgery, and keep Dafalgan in drinking water for approximately 4 days. Leave the mouse to give birth normally approximately five days after the surgery, if done at E13.5 (see Note 14). 


\subsection{Sweat Test}

This protocol relates to the analysis of the phenotype induced by treatment with EDAR pathway modifiers.

1. Prepare a $5 \%$ iodine solution in $100 \%$ ethanol.

2. Prepare a suspension of $1 \mathrm{~g}$ of starch in about $1.5 \mathrm{~mL}$ of olive oil.

3. Immobilize in one hand a mouse aged three weeks or more (Fig. 5a). If necessary, dry rear legs with a soft tissue. (see Note 15).

4. Brush the sole of a foot with a cotton bud dipped into the iodine solution and let the ethanol evaporate for a few seconds (Fig. 5b) (see Note 16).

5. Brush the sole of the foot again with a second cotton bud dipped into the starch in oil suspension (Fig. 5c).

6. Wait for about one minute until dark spots can be observed on foot pads and at finger tips (Fig. 5d and e) (see Note 17).

7. Place lamps on each side of the foot to have appropriate light and take a picture using the camera in macro mode.

8. Wipe the foot with tissue paper and release the mouse.

\subsection{Mouse Skull Preparation for Dental Phenotyping}

This protocol relates to the analysis of the phenotype induced by treatment with EDAR pathway modifiers. 
1. Kill an 8 week-old mouse by $\mathrm{CO}_{2}$ inhalation, or by anesthetic overdose of pentobarbital administered intraperitoneally at $150 \mathrm{mg} / \mathrm{kg}$.

2. With scissors, sever the head from the body at the base of the skull.

3. Surgically clean the head of skin and soft tissues with forceps and scissors. Do not attempt to separate the lower jaw.

4. Insert a $10 \mathrm{~mL}$ syringe with a bent $21 \mathrm{G}$ needle through the base of the skull and flush several times with water to remove the brain. Brain tissue comes out through the foramen magnum of the occiput.

5. Digest the head for $3 \mathrm{~h}$ at $55^{\circ} \mathrm{C}$ in TEN buffer containing $50 \mu \mathrm{g} / \mathrm{mL}$ of freshly added proteinase K. Over-digestion is not recommended as teeth may fall out in subsequent steps, especially in younger mice (see Note 18).

6. Rinse the skull 2-3 times with plenty of water. Manually remove remaining soft-tissues with fine tweezers (see Note 19).

7. Separate the lower jaw from the skull and further clean the bone by soaking in $70 \%$ ethanol for at least 2 days.

8. Bleach the skull and lower jaw in 3\% of hydrogen peroxide freshly diluted in water from a $30 \%$ stock until bones become white (usually $6 \mathrm{~h}$ to overnight), then rinse with plenty of water and dry.

9. Observe teeth with a stereomicroscope equipped with a cooled color CCD camera and using the LAS AF6000 software, or with any other appropriate device.

\section{NOTES}


1. There are restrictions on ordering Pentobarbital, and its use must be properly certified. At the Department of Biochemistry of the University of Lausanne, required amounts can be obtained from the veterinary responsible for the animal facility.

2. We recommend a dose of $2 \mathrm{mg} / \mathrm{kg}$ for EDAR agonists, but higher doses will also work [11]. Half-lives of $48 \mathrm{~h}$ and 11 days have been reported for recombinant Fc-EDA1 and for agonist anti-EDAR antibodies, respectively [11,9]. Therefore, a second administration of Fc-EDA three to four days later can be useful. For function-blocking anti-EDA antibodies, their presence is required throughout the period during which tissues can respond to EDA, justifying more frequent administrations (e.g. every other day) or higher doses (e.g. 4 $\mathrm{mg} / \mathrm{kg}$ ). In support of this hypothesis, tail hair formation was not fully inhibited in the presence of anti-EDA antibodies, suggesting the possibility that some EDA in the tail escaped inhibition [12]. It is known that an exposure to Fc-EDA as short as $3.5 \mathrm{~h}$ is sufficient to induce tail hair formation [15].

3. Red lamps can burn and should be kept at least $20 \mathrm{~cm}$ away from mice.

4. Using this administration route, $\mathrm{EC}_{50}$ of 0.1 to $0.3 \mathrm{mg} / \mathrm{kg}$ have been reported with both anti-EDAR antibodies and Fc-EDA recombinant protein for induction of tail hair and sweat glands in newborn Eda-deficient pups [11,9].

5. Glass Hamilton syringes do not enter conventional tubes, and the needle is too short to reach the bottom. Filling the syringe from a drop on parafilm reduces the risk of bending or clogging the needle, but the drop should be prepared just before use to minimize evaporation. Insulin syringes may also be used, but with an increased risk of liquid leakage out of the abdomen after injection. 
6. The procedure is easier when pups have not yet fed. It is not uncommon for some liquid to leak out when the needle is removed, especially in well-hydrated pups. Record such events as they can be an explanation for suboptimal treatment outcomes, although such leakage often has no or little impact as the leaked fluid is not necessarily the injected solution.

7. Blood volume in mice is $70-80 \mathrm{~mL} / \mathrm{kg}$ and should be calculated on the lower limit. Natural compensation mechanisms can cope with loss of up to $20 \%$ of blood volume in a period of 14 days, which is equivalent to $280 \mu \mathrm{L}$ for a $20 \mathrm{~g}$ mouse. This volume can be taken in a single bleed, or in several smaller bleeds.

8. Blood sampling from the facial vein can also be performed without anesthesia.

9. The facial vein is under the skin, not deeply situated. Best results are obtained with a light pinch of the neck skin. A deep pinch does not help, causes damage and can even induce bleeding in the ear.

10. To prepare serum, let blood coagulate for $2 \mathrm{~h}$ at $37^{\circ} \mathrm{C}$ or overnight at $4^{\circ} \mathrm{C}$. Spin tubes for $20 \mathrm{~min}$ at $13^{\prime} 000 \mathrm{rpm}\left(16^{\prime} 200 \mathrm{x} \mathrm{g}\right)$ at room temperature in a table top centrifuge. Collect supernatant, which will usually yield $30-40 \%$ of the initial volume of blood.

11. Oxygen and isoflurane reach the mask through a cylinder-like piece. A home-made mask can be obtained by cutting the finger of a nitrile or vinyl glove, pulling it over the open end of the cylinder and keeping it in place with sticky tape. Cut the very tip of the glove finger with scissors to create a round opening in which the snout of the anesthetized mouse can be placed.

12. The incision should not be longer than necessary. $1.5 \mathrm{~cm}$ is enough to extract uterine horns. 
13. Before starting the laparotomy procedure, fill the syringe with the injection solution for all fetuses, provided they all receive the same treatment. For this purpose, aspirate the solution laid as a drop on a piece of parafilm (see Note 5). The Hamilton syringe can be equipped with a 33G or a 34G needle. We prefer a 33G needle in which clogging is less likely than in the very fine $34 \mathrm{G}$ needle.

14. Leave the mouse as undisturbed as possible, but perform daily examination of different criteria (activity, posture, movement and gait, coat condition, grooming, breathing, alertness, dehydration, eyes and nose, surgical wound) using a score sheet. In case of an inflamed surgical wound, treat with a Bepanthen Plus cream. In case of suspicion of infection, treat with antibiotics upon prescription from the veterinarian.

15. Sweat glands require proper innervation to become fully functional. Sweat tests performed before weaning either do not work or may give unreliable results.

16. If the cotton bud is reused several times, the iodine amount applied will increase as a result of repeated ethanol evaporation, which may increase background. Change the cotton bud after about 3 to 4 mice.

17. A spotty background of small dark spots may appear from time to time. If this is the case, immediately discard and renew the suspension of starch in oil.

18. The bones on the top of the skull (the parietal and interparietal bones) can easily detach from the skull, especially in younger mice.

19. It can be more comfortable to perform this procedure under a binocular magnifier.

Acknowledgments: P.S. is supported by the Swiss National Science Foundation [grant 310030A_176256]. 
Conflict of interest: Authors declare no competing financial interests.

\section{REFERENCES}

1. Kere J, Srivastava AK, Montonen O, Zonana J, Thomas N, Ferguson B, Munoz F, Morgan D, Clarke A, Baybayan P, Chen EY, Ezer S, Saarialho-Kere U, de la Chapelle A, Schlessinger D (1996) X-linked anhidrotic (hypohidrotic) ectodermal dysplasia is caused by mutation in a novel transmembrane protein. Nat Genet 13 (4):409-416. doi:10.1038/ng0895-409

2. Srivastava AK, Pispa J, Hartung AJ, Du Y, Ezer S, Jenks T, Shimada T, Pekkanen M, Mikkola ML, Ko MS, Thesleff I, Kere J, Schlessinger D (1997) The Tabby phenotype is caused by mutation in a mouse homologue of the EDA gene that reveals novel mouse and human exons and encodes a protein (ectodysplasin-A) with collagenous domains. Proc Natl Acad Sci U S A 94 (24):1306913074. doi:10.1073/pnas.94.24.13069

3. Headon DJ, Emmal SA, Ferguson BM, Tucker AS, Justice MJ, Sharpe PT, Zonana J, Overbeek PA (2001) Gene defect in ectodermal dysplasia implicates a death domain adapter in development. Nature 414 (6866):913-916. doi:10.1038/414913a

414913a [pii]

4. Headon DJ, Overbeek PA (1999) Involvement of a novel Tnf receptor homologue in hair follicle induction. Nat Genet 22 (4):370-374. doi:10.1038/11943

5. Monreal AW, Ferguson BM, Headon DJ, Street SL, Overbeek PA, Zonana J (1999) Mutations in the human homologue of mouse dl cause autosomal recessive and dominant hypohidrotic ectodermal dysplasia. Nat Genet 22 (4):366-369. doi:10.1038/11937

6. Hammersen JE, Neukam V, Nusken KD, Schneider H (2011) Systematic evaluation of exertional hyperthermia in children and adolescents with hypohidrotic ectodermal dysplasia: an observational study. Pediatr Res 70 (3):297-301. doi:10.1203/PDR.0b013e318227503b

7. Cui CY, Durmowicz M, Ottolenghi C, Hashimoto T, Griggs B, Srivastava AK, Schlessinger D (2003) Inducible mEDA-A1 transgene mediates sebaceous gland hyperplasia and differential formation of two types of mouse hair follicles. Hum Mol Genet 12 (22):2931-2940. doi: $10.1093 / \mathrm{hmg} / \mathrm{ddg} 325$

$\operatorname{ddg} 325$ [pii]

8. Gaide O, Schneider P (2003) Permanent correction of an inherited ectodermal dysplasia with recombinant EDA. Nat Med 9 (5):614-618. doi:10.1038/nm861

9. Schneider H, Faschingbauer F, Schuepbach-Mallepell S, Korber I, Wohlfart S, Dick A, Wahlbuhl M, Kowalczyk-Quintas C, Vigolo M, Kirby N, Tannert C, Rompel O, Rascher W, Beckmann MW, Schneider P (2018) Prenatal correction of X-linked hypohidrotic ectodermal dysplasia. N Engl J Med 378 (17):1604-1610. doi:10.1056/NEJMoa1714322

10. Hermes K, Schneider P, Krieg P, Dang A, Huttner K, Schneider H (2014) Prenatal therapy in developmental disorders: drug targeting via intra-amniotic injection to treat X-linked hypohidrotic ectodermal dysplasia. J Invest Dermatol 134 (12):2985-2987. doi:10.1038/jid.2014.264

11. Kowalczyk C, Dunkel N, Willen L, Casal ML, Mauldin EA, Gaide O, Tardivel A, Badic G, Etter AL, Favre M, Jefferson DM, Headon DJ, Demotz S, Schneider P (2011) Molecular and therapeutic characterization of anti-ectodysplasin A receptor (EDAR) agonist monoclonal antibodies. J Biol Chem 286 (35):30769-30779. doi:10.1074/jbc.M111.267997

M111.267997 [pii] 
12. Kowalczyk-Quintas C, Willen L, Dang AT, Sarrasin H, Tardivel A, Hermes K, Schneider H, Gaide O, Donze O, Kirby N, Headon DJ, Schneider P (2014) Generation and characterization of function-blocking anti-ectodysplasin A (EDA) monoclonal antibodies that induce ectodermal dysplasia. J Biol Chem 289 (7):4273-4285. doi:10.1074/jbc.M113.535740

13. Del-Pozo J, MacIntyre N, Azar A, Headon D, Schneider P, Cheeseman M (2019) Role of ectodysplasin signalling in middle ear and nasal pathology in rat and mouse models of hypohidrotic ectodermal dysplasia. Dis Model Mech 12 (4). doi:10.1242/dmm.037804

14. Kowalczyk-Quintas C, Schuepbach-Mallepell S, Willen L, Smith TK, Huttner K, Kirby N, Headon DJ, Schneider P (2015) Pharmacological stimulation of Edar signaling in the adult enhances sebaceous gland size and function. J Invest Dermatol 135 (2):359-368. doi:10.1038/jid.2014.382

15. Swee LK, Ingold-Salamin K, Tardivel A, Willen L, Gaide O, Favre M, Demotz S, Mikkola M, Schneider P (2009) Biological activity of ectodysplasin A is conditioned by its collagen and heparan sulfate proteoglycan-binding domains. J Biol Chem 284 (40):27567-27576. doi:M109.042259 [pii]

10.1074/jbc.M109.042259

FIGURE LEGENDS
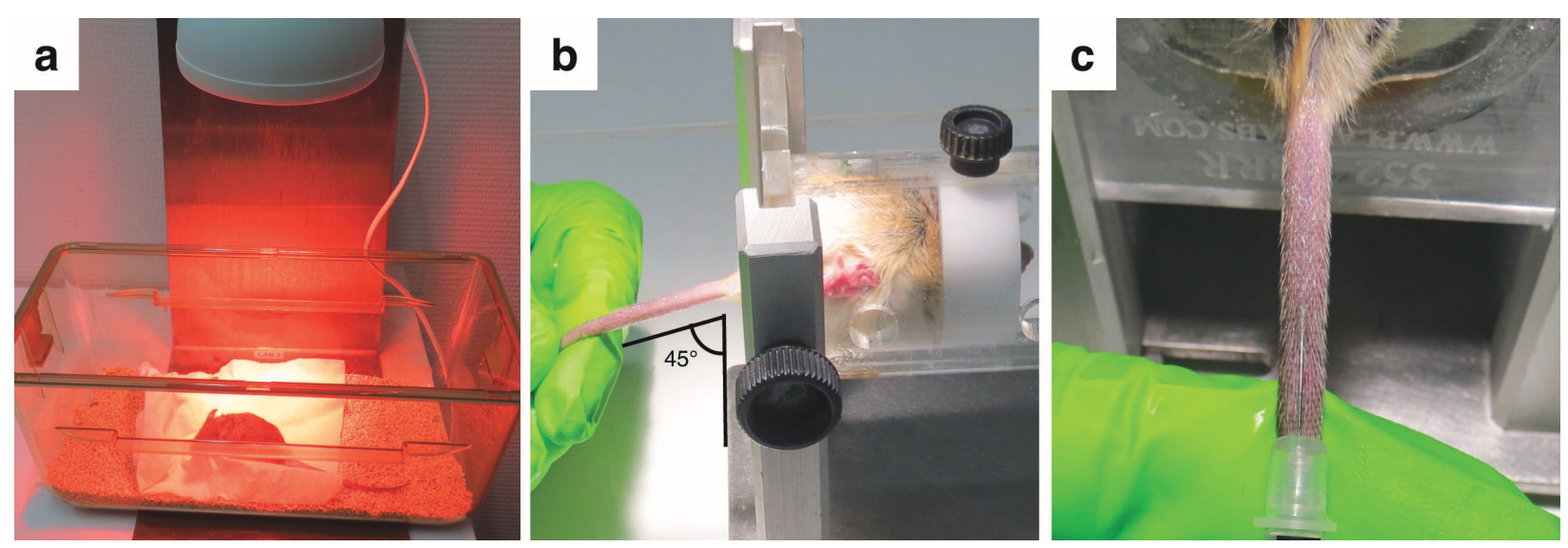

Fig. 1. Intravenous injection in the tail vein of an adult mouse.

(a). Mouse placed under a red lamp to stimulate veins dilatation.

(b). Mouse immobilized in the lateral position in a restrainer with the tail held down with an angle

(c). Tail of a mouse moisturized with a fine spray of $70 \%$ ethanol to render the vein more visible.

A needle almost parallel to the tail is inserted into the vein just below the skin. 


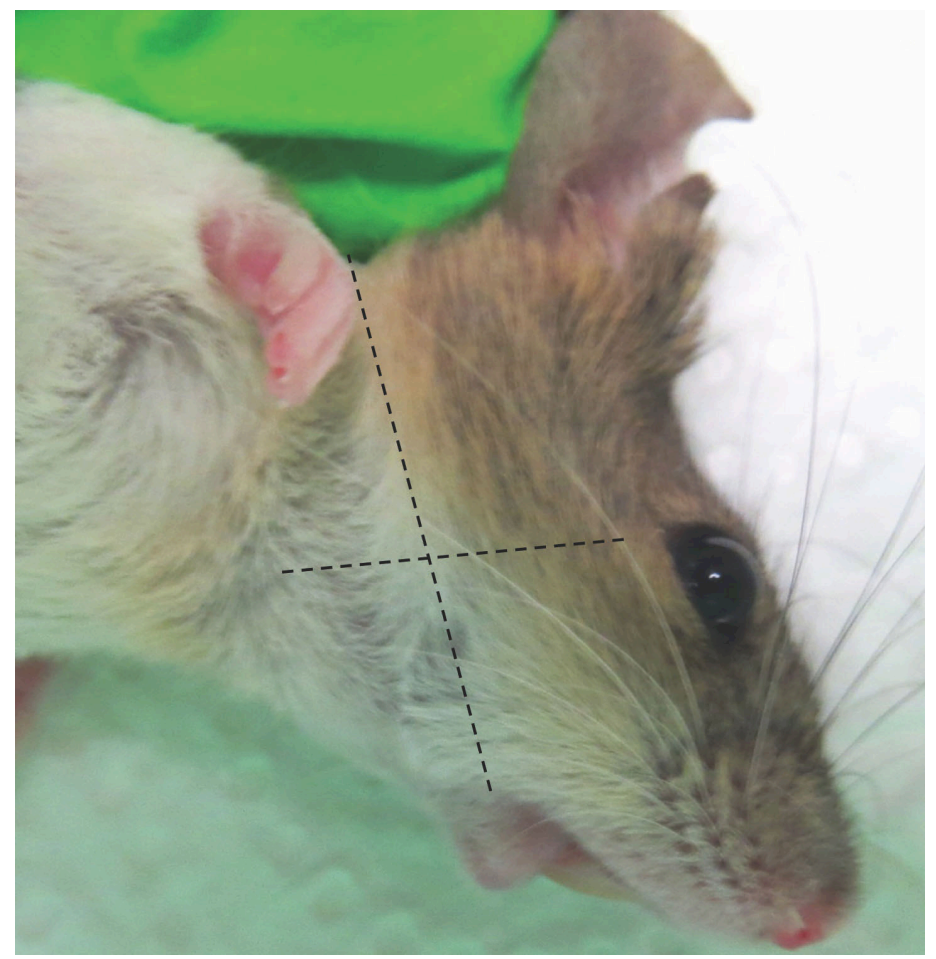

Fig. 2. Blood collection from the facial vein.

Mouse lightly anesthetized with 3\% isoflurane and held by the neck. The virtual dashed lines intersect above the facial vein, which lies just under the skin and can be pricked with a shallow hit of a lancet. 

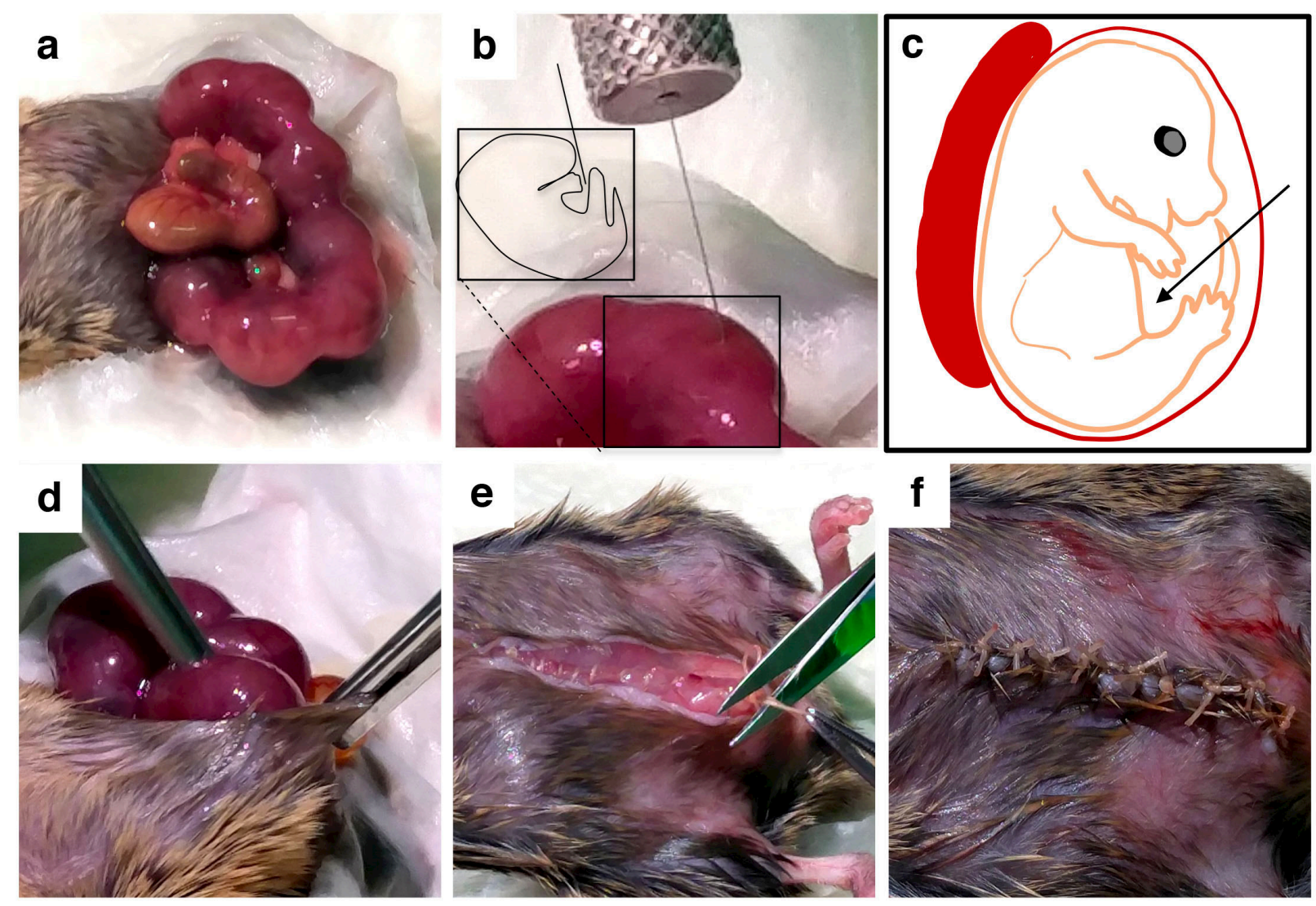

Fig. 3. Intra amniotic fluid administration procedure.

(a). Anesthetized mouse placed on the back with the abdominal cavity opened approximately 1.5 $\mathrm{cm}$ by midline laparotomy, and with both uterine horns pulled out completely from the cavity and placed on moistened tissue papers around the opening. In this picture, there is a total of 7 fetuses arranged along an inverted " $\mathrm{C}$ ". The mass in the middle is the intestine.

(b). Injection in the amniotic sac of the second fetus on the top of panel A using a glass syringe with a $33 \mathrm{G}$ needle. The amniotic sac is gently held with forceps, but these were removed for the purpose of taking pictures. The position of the fetus that can be seen by transparency is shown as a line drawing, along with the injection needle.

(c). Scheme of the position of a fetus inside the amniotic sac, which can be seen by transparency through the membrane. The arrow points at the place between the upper and lower limbs where the protein should be injected without touching the fetus.

(d). Placement of uterine horns back into the abdominal cavity. The incised abdominal wall is lifted on one side with a pair of forceps while gently putting back in place the closest uterine horn. (e). Closure of the abdominal wall by continuous suture.

(f). Suture of the skin with several interrupted stitches.

Pictures of this figure were made on one of the mice analyzed in reference [9]. 

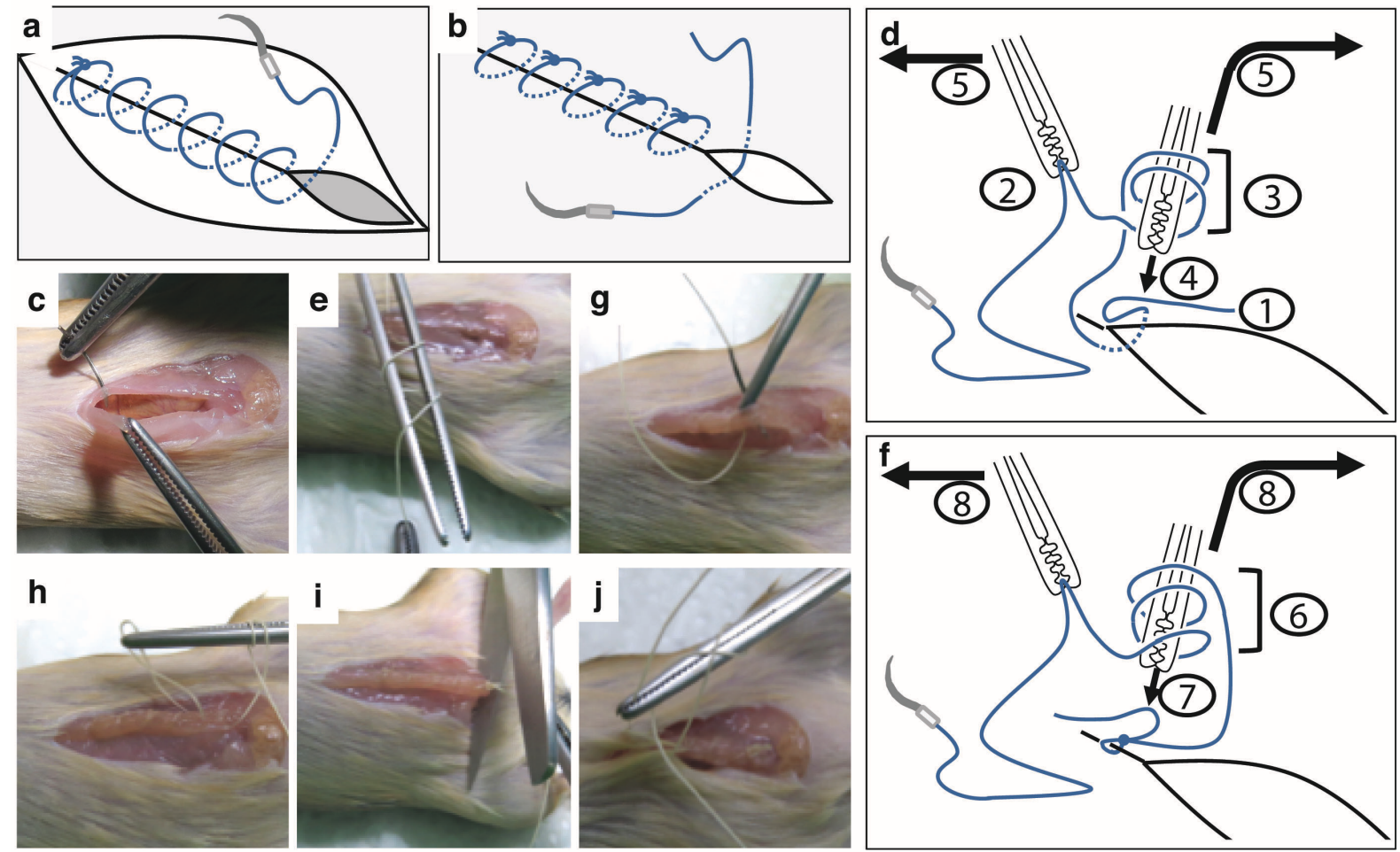

Fig. 4. Continuous and interrupted sutures procedures.

(a). Scheme of a continuous suture, used to close the abdominal wall.

(b). Scheme of single interrupted stitches, used to close the skin.

(c). First step of the continuous suture of the abdominal wall.

(d). Scheme for the making of the first part of a surgeon's knot. About $2 \mathrm{~cm}$ of thread is left on the right side of the opening (1). The thread on the other side is held with forceps (2) and wrapped twice clockwise around a second pair of forceps (3). The small end of the thread is grabbed with the second pair of forceps (4). Forceps are gently moved apart (5) so that the wrapped thread slides along the forceps to create the first part of the knot.

(e). The thread is wrapped twice clockwise on the extremity of forceps.

(f). Scheme of the second and last part of making a surgeon's knot. The thread is wrapped twice counter-clockwise on the forceps (6). The small extremity of the thread is grabbed with those same forceps (7), then forceps are gently moved apart to complete the knot.

(g). Closure of the abdominal wall with a continuous suture.

(h). Making of the first part of the surgeon's knot at the end of the continuous suture. Same procedure as shown in panel D, except that a loop of thread, instead of the extremity of a thread, is grabbed.

(j). Suture of the skin with single interrupted stitches.

Pictures of this figure were made on a dead, non-pregnant mouse. 

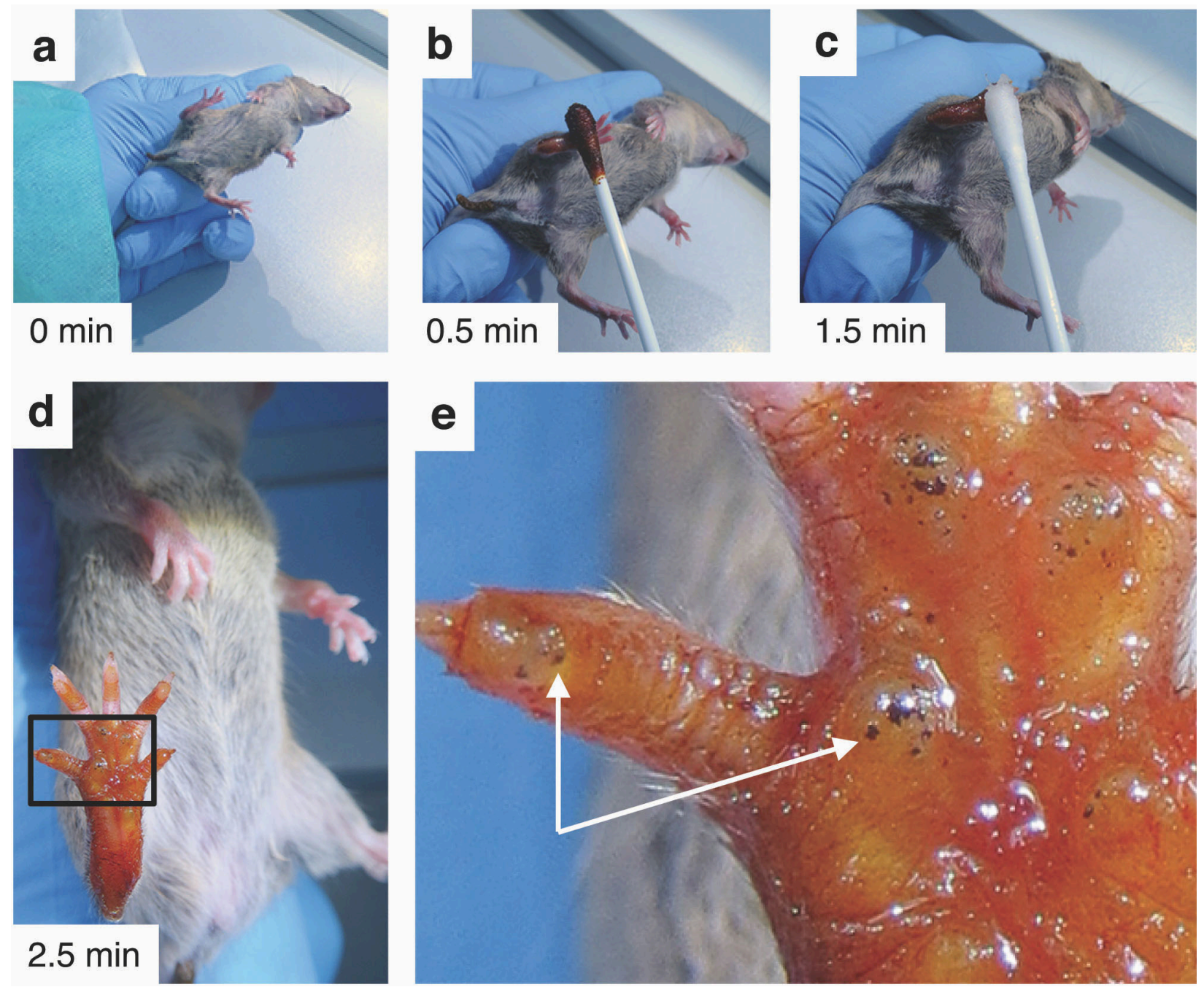

Fig. 5. Starch-iodine sweat test.

(a). Mouse restrained in one hand.

(b). Application of iodine in ethanol with a cotton tab.

(c). Application of starch in oil.

(d). Visualization of sweat output as dark spots.

(e). Enlargement of the area shown in panel D. White arrows point at functional sweat glands. The approximate cumulative time of the procedure is shown at the bottom left of panels a-d. 